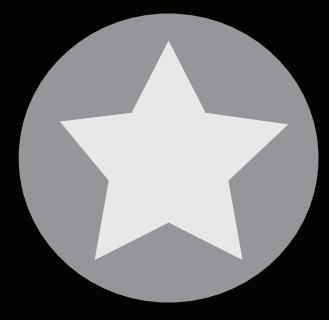

\title{
Marilyn Monroe:
} la construcción de

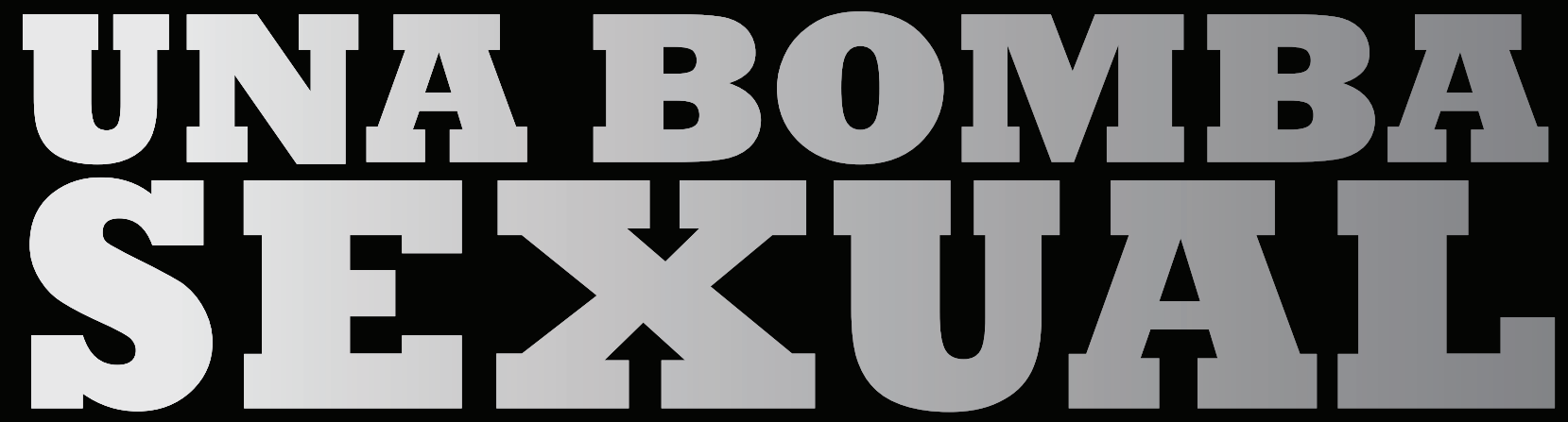

La mítica actriz del Hollywood clásico se convirtió en un emblema de la mujer deseada, irresistible, excitante. Hoy es una influencia fundamental en la cultura popular. ¿De qué manera podemos entender cómo su imagen se fue formando en la pantalla para llegar a ese estatus? Revisemos algunos de los signos de la construcción del personaje, destinado a convertirse en estrella cinematográfica, que plantea el especialista Richard Dyer. 


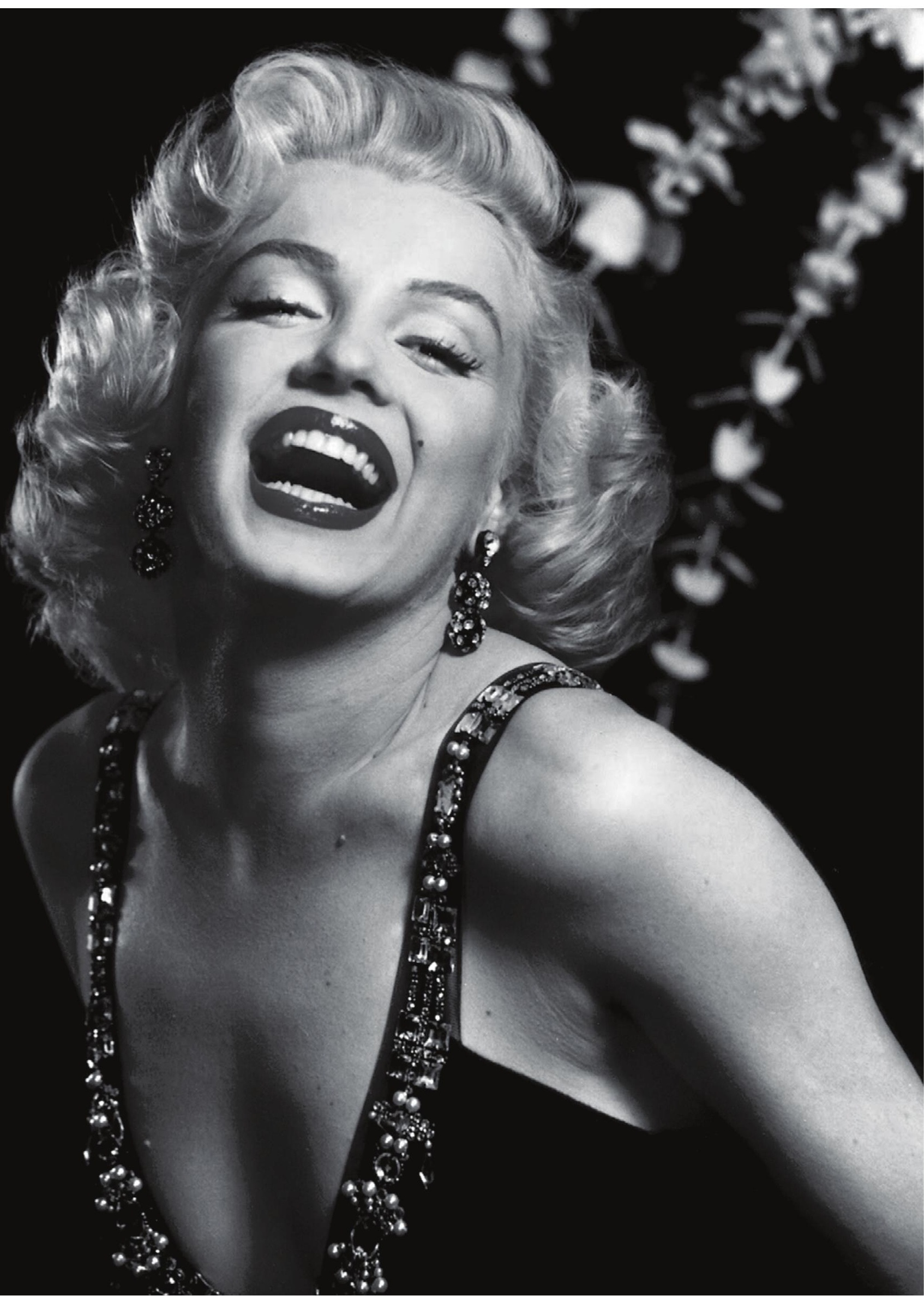


Hablar del estrellato es hablar de un fenómeno con varias aristas. Richard Dyer, en su libro Las estrellas cinematográficas. Historia, ideología, estética (2001), define a estas figuras como productos industriales: "Las estrellas son imágenes en textos mediáticos, y como tales son producto de Hollywood (o de donde sea)..." (Dyer 2001: 25). En el libro From reverence to rape: Treatment of women in the movies (1987), Molly Haskell señala que las estrellas son reflejos de fantasías y de modas:

Mucho más que los hombres, las mujeres (estrellas) eran los vehículos de fantasías de hombres y mujeres, y los barómetros de las modas. Como un espejo de dos caras, que une el pasado inmediato con el futuro inmediato, las mujeres en las películas reflejaban, perpetuaban, y en cierta forma ofrecían innovaciones en los roles sociales de la mujer (Haskell 1987: 12).

Junto a muchas estrellas clásicas de Hollywood, de la talla de James Dean, Ava Gardner, Marlene Dietrich o Jean Harlow, se encuentra Marilyn Monroe, quien representa muy bien las afirmaciones de Maskell. Ella fue la rubia debilidad, que encarnaba una figura deslumbrante, envidiada por las mujeres y deseada por hombres. A la vez, impuso una moda en cuanto a la vestimenta femenina.

\section{Origen del Star system}

Las estrellas van siendo moldeadas por la industria, con un aparato de mercadotecnia bien consolidado que encauza las demandas del público. Por ello, la estrella clásica hollywoodense es en muchos casos semejante a sí misma de película a película, sin que se presenten mayores variaciones de su imagen. No ocurre lo mismo con los actores del Hollywood contemporáneo, como Johnny Depp, quien interpreta roles muy distintos entre sí en cintas como El joven manos de tijeras, Inhala o Piratas del Caribe. La Monroe, en cambio -aunque con algunas excepciones o matices, como se indicará-, interpretaba de forma casi constante a la misma rubia ingenua pero sensual.

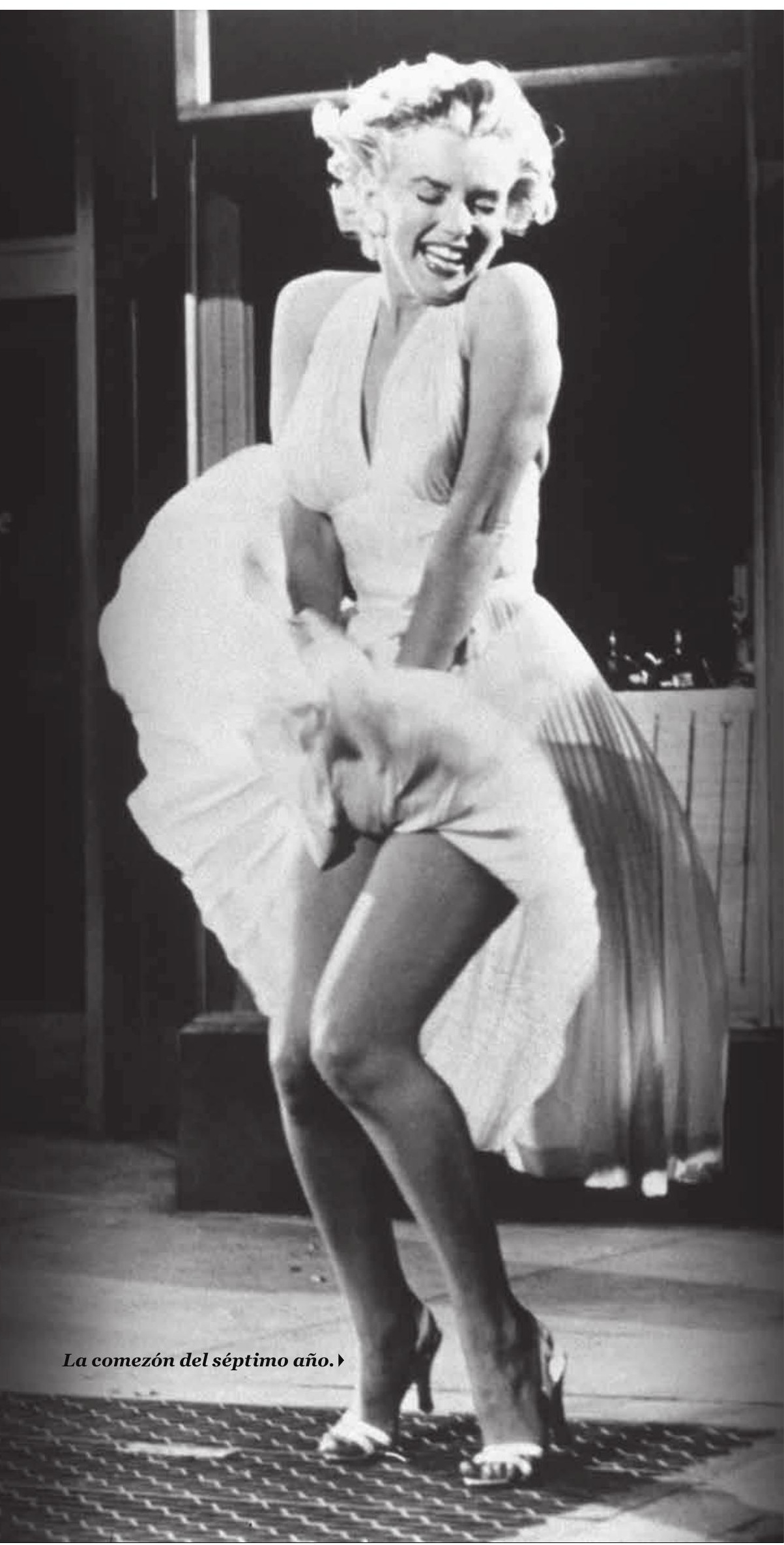




\section{Billy Wilder, director de $L a$}

comezón del

séptimo año, alguna

vez dijo que el

personaje de

Marilyn no requería

nombre, pues su

atractiva presencia

la convertía de

manera inmediata

en lo más llamativo

del filme.

La industria fílmica decide cuál es la imagen a proyectar de las distintas estrellas. Para Dyer, hay un lado manipulador en cómo los medios de comunicación colocan ante el espectador la imagen de las artistas:

Es decir, la 'aportación' de los medios de comunicación tiene un 'efecto' dado (en este caso, aceptación pasiva) en el sujeto humano, sin la intervención de la mente o de la consciencia del sujeto. (...) Nuestra posición en relación con las estrellas-comomanipulación depende, pues, de los modelos de conducta de los medios de comunicación en general (Dyer 2001: 30).

En ese sentido, la figura de Marilyn Monroe se vio plasmada no solo en las películas sino también en portadas de revistas y catálogos de moda. La estrella debe ser de algún modo omnipresente, concentrando algunos rasgos muy particulares.

Por eso, la industria mediática no debía mostrar a una Marilyn sensible, en otras palabras "humana", sino a una Marilyn convertida en un ser superior, que iba más allá de cualquier condición femenina: una bomba sexual. Aunque cabe destacar la paradoja que destaca Richard Griffith dentro del texto de Dyer: “[...] ninguna maquinaria, por ella misma ni a través de ella, ha construido una estrella. Esto sucede en las profundidades del inconsciente colectivo" (Griffith, citado por Dyer 2001: 35). A pesar de que se culpe a estos "monstruos" de la industria de ser creadores de personajes carismáticos y casi inalcanzables, vemos que en realidad el nacimiento de una estrella también depende de la respuesta del propio público.

Entonces, la estrella, en palabras del propio Dyer, es una construcción tanto de los creadores de cine como del público. Así, se encontrará conformada por varios signos, como el conocimiento previo de público, el nombre, la apariencia, entre otros.

\section{Construyendo a Marilyn}

¿Cómo encaja Marilyn Monroe en esta tipología de signos del personaje/ estrella planteada por Dyer? Veamos:

El conocimiento previo del público.- Uno puede acudir a ver una película con alguna predisposición, relacionada al nombre de esta o a los personajes, tal como ocurre en la película de 1959 Una Eva y dos Adanes (originalmente titulada Some like it hot, que significa Algunos las prefieren calientes), poseedora de un título que anuncia a un personaje de connotaciones sexuales como el que interpreta Monroe. No obstante, el caso de la última película de Marilyn, Los inadaptados (1961), es singular. Si bien ella no deja de interpretar en esta película de John Huston el papel de la mujer sexy, se nota en ella una dimensión opaca e inestable, más próxima a cómo era en el mundo lejano de las cámaras.

El nombre.- Hollywood no quiere dar una imagen real de sus estrellas. Por el contrario, busca que el público las recuerde por sus películas, y las características y gestos que plasman en ellas. Una vez que ella, originalmente llamada Norma Jeane Baker, empezó a ser famosa como modelo. los productores le sugirieron cam- biar de nombre para lograr un atractivo comercial. Finalmente, decidieron elegir Marilyn, por la afamada actriz del Broadway de los años veinte llamada Marilyn Miller, y Monroe, por ser el apellido de soltera de su madre. Su nombre conserva parte de la identidad original de la actriz, pero a la vez agrega un componente de glamour por la referencia a aquella actriz de Broadway.

La apariencia.- Este rubro determina en parte cómo se percibirá la personalidad de la estrella. En el caso de Monroe, su fisonomía no era la de una mujer promedio. Se caracterizaba por tener un cuerpo voluptuoso, aunque sin ser exagerado en sus formas. No obstante, su belleza natural fue perfeccionada por la industria, con la realización de procedimientos quirúrgicos en su rostro (afinación del mentón, operación para reducir el volumen de los pómulos, intervención para respingar su nariz), así como con "trucos" como el uso de lentes de contacto que hacían que su mirada luzca más impactante, la pintura negra en el pequeño lunar que tenía cerca de la boca, y la saturada pintura roja en sus labios. Así, se transformó en una invitación irrechazable de deseo y placer.

La vestimenta y los peinados se expresan también como signos importantes del "personaje" Marilyn. Fue una rubia platinada, de vestidos que relucían su cuerpo. En Nunca fui santa (1956), cinta en la que interpreta a una cantante de cabaret, luce unas prendas ajustadas, bastante escotadas y casi transparentes. Por otro lado, está el clásico vestido blanco de vuelo, con el que aparece en La comezón del séptimo año (1955), que inmortalizara su imagen de halo sexy.

En el libro Marilyn in fashion: The induring influence of Marilyn Monroe, de Christopher Nickens y George Zeno, se señala que la mítica actriz logró con sus vestidos, hechos a la medida exacta de su cuerpo, imponer una moda:

Monroe fue una visionaria del estilo de sus elecciones de moda a futuro que han trascendido cualquier era específica. Más que ninguna otra figura famosa de su 
época, ella tomó conciencia de la confección de ropa 'a medida del cuerpo' inspirando a muchos diseñadores como Alexander McQueen, Jean Paul Gaultier, Thierry Mugler e Yves St. Laurent. Monroe se adelantó al tiempo, no sólo en la moda también en sus diarios entrenamientos con pesas, ella inspiró a muchas figuras al cuidado del cuerpo. Su presencia no sólo sirvió de modelo plenamente estético más que nada de respeto por la propia presencia femenina en donde más importaba las formas y contornos del cuerpo que la ropa. (Nickens y Zeno 2012: 131-132).

El habla del personaje.- Marilyn Monroe es conocida a nivel mundial no solo por haber poseído una belleza inigualable, sino también por ser dueña de una voz sensual pero a la vez cándida. Según Robert Greene, en su libro El arte de la seducción, eso hacía de Marilyn una mujer más deseada, por despertar instintos paternales, de protección, en los hombres:

Su voz siempre había sido atractiva: era la de una niña. Pero en el cine tuvo limitaciones hasta que alguien le enseñó a hacerla más grave, con lo que ella la dotó de los profundos y jadeantes tonos que se convertirían en la marca distintiva de su poder seductor, una mezcla de la niña pequeña y la pequeña arpía. Antes de aparecer en el foro, o incluso en una fiesta, Marilyn pasaba horas frente al espejo. La mayoría creía que era por vanidad, que estaba enamorada de su imagen [...]. A Marilyn Monroe le encantaba el efecto que su cuerpo podía tener en la libido masculina. Afinaba su presencia física como un instrumento, con lo que terminaba por exudar sexo y conseguir una apariencia glamurosa y exuberante. Otras mujeres sabían tantos trucos como ella para incrementar su atractivo sexual, pero lo que distinguía a Marilyn era un elemento inconsciente. Su biografía la había privado de algo decisivo: afecto. Su mayor necesidad era sentirse amada y deseada, lo que la hacía parecer constantemente vulnerable, como una niña ansiosa de protección (Greene 2001: 44-45).

Ese rasgo vocal de la estrella se puede apreciar en Los caballeros las prefieren rubias (1953), en la que junto a la bella Jane Russell interpreta a una despampanante cazafortunas, valiéndose de sus gestos como de su voz sexy e inocentona para seducir a algún caballero adinerado que se le cruce en el camino. Lo mismo sucede en la hilarante Una Eva y dos Adanes, en la que su voz, así como su apariencia, atrapa al no tan masculino personaje llamado Daphne, interpretado por Tony Curtis. La canción "I wanna be loved by you" que ella interpreta en esta película de Billy Wilder, concentra muy bien las características sensuales e infantiles de su voz.

Lo curioso es que a pesar de que Marilyn interpretaba un personaje, a su vez daba a conocer parte de su forma de ser. Se mostraba por medio de esa voz como una mujer necesitada de cariño, insegura, que sabía que su cuerpo podía ser un medio para lograr diferentes objetivos.

El habla de los demás.- En la mayoría de las películas de Marilyn Monroe se suelen anticipar su aparición, mencionándose así la irrupción de una presencia femenina que connota un erotismo hasta animal. En la película Los inadaptados, en una escena en la que aparece Clark Gable conversando con Eli Wallach, comenta que Roslyn (Monroe) es como una bestia indomable, y bajo ese manto de belleza se esconde una máquina de carne.

Con respecto a cómo es llamada en otras películas, encontramos que el personaje de Monroe en Nunca fui

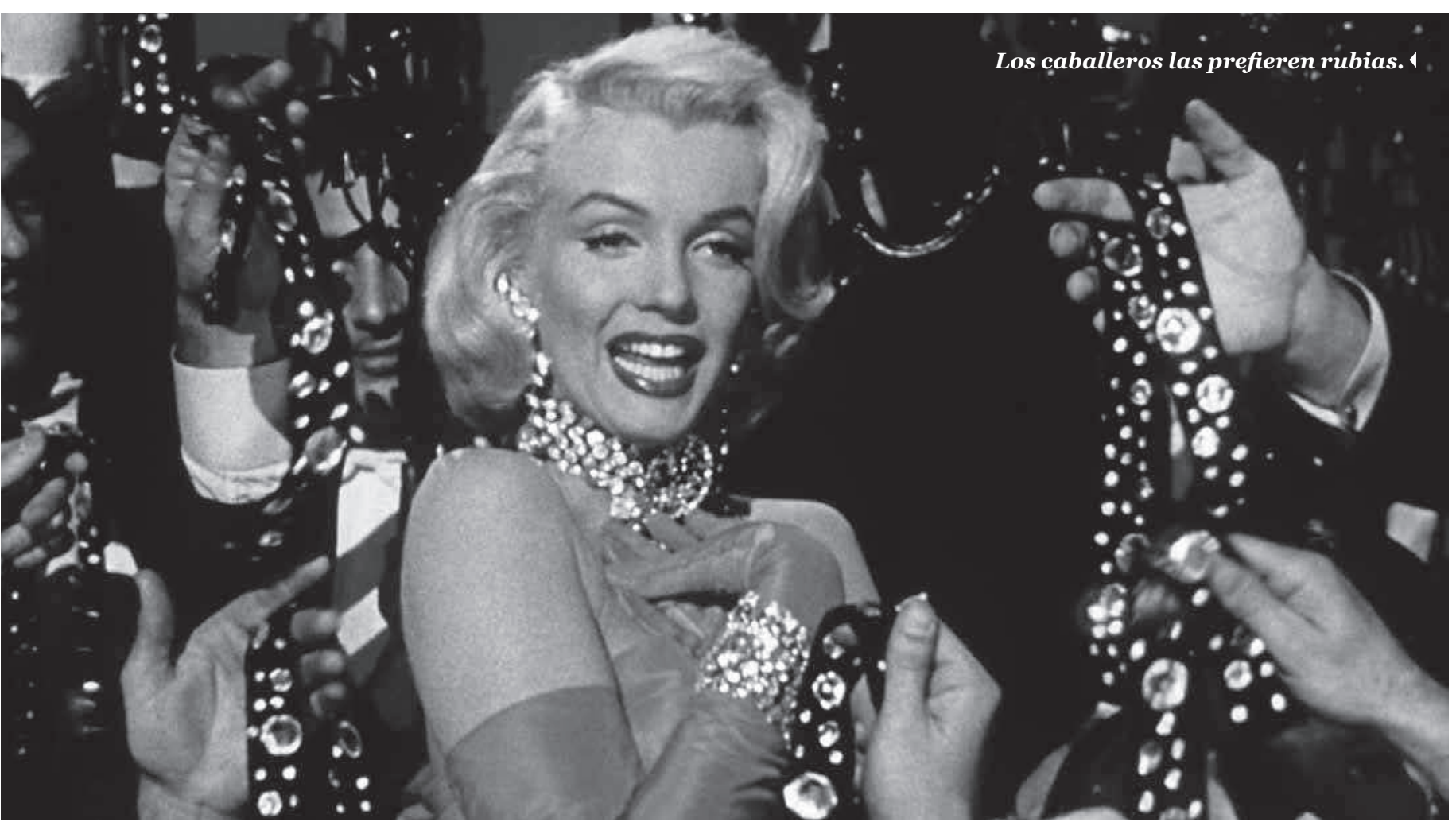


santa es llamada Cherie. Sin embargo, el personaje de Don Murrray, al referirse a ella, pronuncia 'cherry' (cereza), por la visión lujuriosa que tiene de ella. En La comezón del séptimo año todos los personajes tienen nombre menos la misma Marilyn, quien es llamada simplemente como "la chica". El director de la cinta, Billy Wilder, alguna vez dijo que ella era un personaje que no requería nombre, pues su atractiva presencia la convertía de manera inmediata en lo más llamativo del filme.

El gesto.- Dyer lo clasifica en dos tipos. Uno está relacionado con aquellos gestos que dependen de reglas sociales o convenciones, lo que lleva a un determinado comportamiento ante el público. Lo que ocurría con Marilyn era que había ensayado en privado tantas veces su tono de voz, que en público tenía una especie de papel aprendido, luciendo una pronunciada sonrisa que aparentaba felicidad. El otro tipo de gesto se asocia a códigos informales, involuntarios, que revelan la verdadera personalidad de la estrella. Lo que ocurría con Marilyn era algo muy particular, pues aunque a través de sus películas o fotografías mostraba una imagen imponente, en los rodajes olvidaba los guiones, llegaba muy tarde, tenía que repetir muchas veces los diálogos. Así, se descubría a la verdadera Marilyn, una mujer lo suficientemente bella para cautivar al mundo, pero muy frágil e inestable para mantener su afamada vida.

Ella es la muestra de que el proceso de construcción de una estrella se basa en la mezcla de un carisma natural con una serie de artificios característicos de la industria cinematográfica. Y esa es una luminosa combinación que puede esconder la más honda oscuridad de un mito.

\section{Bibliografía}

Dyer, Richard (2001). Las estrellas cinematográficas. Historia, ideología, estética. Barcelona: Paidós.

Greene, Robert (2001). El arte de la seducción. México D.F.: Océano.

Haskell, Molly (1987). From reverence to rape: Treatment of women in the movies. Chicago: University of Chicago Press.

Nickens, Christopher y George Zeno. Marilyn in fashion. The induring influence of Marilyn Monroe. Philadelphia-Londres: Running Press/Perseus Book Group.

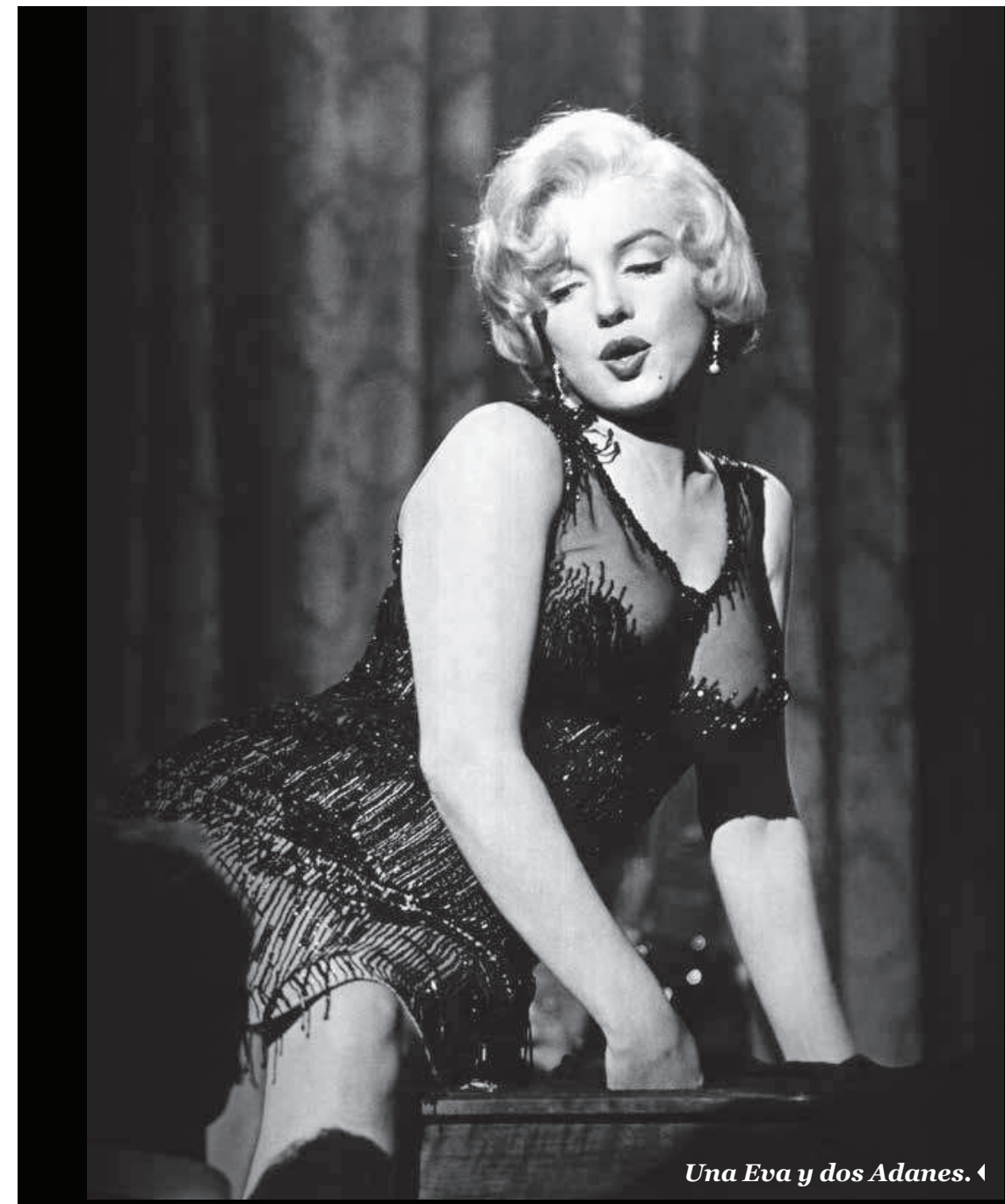

\section{NUNCA FUI SANTA}

La voz de Marilyn Monroe era excitante para muchos no solo por su textura sensual y a la vez infantil, sino también por sus confesiones provocadoras. Su fantasía de estar desnuda en una iglesia fue una prueba de ello. Escuchémosla:

"Mi deseo de llamar la atención, creo, tiene que ver con mis visitas a la iglesia los domingos. Apenas estaba sentada y escuchaba el sonido del órgano, y a la gente cantando, sentía el impulso de quitarme la ropa. Sentía la necesidad de pararme desnuda en nombre de Dios para que todos me vieran [...]. A veces tenía que rezarle profundamente y suplicarle que me detuviera para no hacerlo.

Incluso tuve sueños al respecto. En uno de ellos entraba a la iglesia vistiendo un polisón pero sin ropa interior. La gente estaría recostada sobre el suelo entre los pasillos de la iglesia, y yo pasaría sobre ellos, y todos levantarían la mirada hacia mí.

Mis ganas de aparecer desnuda y mis sueños sobre eso no tienen ningún sentido de vergüenza o pecaminoso. Soñar con gente mirándome me hace sentir menos sola”. ${ }^{1}$

${ }^{1}$ Monroe, M. y B. Hecht. (2006). My story. Nueva York: Taylor Trade, pp. 13-14. (Traducción nuestra). 